Published by Al-Nahrain College of Medicine P-ISSN 1681-6579

E-ISSN 2224-4719

Email: iraqijms@colmed-alnahrain.edu.iq

http://www.colmed-alnahrain.edu.iq

http://www.iraqijms.net

Iraqi JMS 2020; Vol. 18(1)

\title{
Amorphophallus konjac and Polycystic Ovary Syndrome
}

\author{
Ehab S. Hussein ${ }^{1} M S c$, Ahmed R. Abu-Raghif ${ }^{2}$ PhD, Hala A. Almuaid ${ }^{3}$ CABOG \\ ${ }^{1}$ Baghdad Health Directorate - Al-Karkh, Ministry of Health, Iraq, ${ }^{2}$ Dept. of Pharmacology and Therapeutics, College of \\ Medicine, Al-Nahrain University, Baghdad, Iraq, ${ }^{3}$ Dept. of Obstetrics and Gynecology, College of Medicine, Al-Nahrain \\ University, Baghdad, Iraq
}

\section{Abstract \\ Background}

Objective

Methods

Results

Conclusion

Keywords

Citation

Polycystic ovary syndrome (PCOS) is that the commonest reproductive endocrine disorder among women of reproductive age, affecting high of population worldwide. It's the most typical multisystem endocrinopathy having diverse etiopathogenesis in women, causing menstrual irregularities, hirsutism and anovulatory infertility.

To determine the effect of Glucomannan, Amorphophallus konjac supplementation on body weight, body mass index (BMI), Insulin level, insulin resistance indexes, fasting glucose level, luteinizing hormone (LH) level, testosterone, sex hormone binding globulin (SHBG) and lipid profile in over weight and obese women patients with PCOS.

Thirty obese and overweight women with PCOS, mean BMI $=32 \mathrm{~kg} / \mathrm{m}^{2}$ with mean age $=29 \mathrm{yr}$ were enrolled in the study. They were received Glucomannan in a dose of $2300 \mathrm{mg}$ daily) for three months. The parameters were measured before and after three months of treatment are BMI, fasting plasma glucose, serum insulin levels, Insulin resistance indexes; homeostasis model assessment of $\beta$-cell function (HOMA-B), homeostasis model assessment of insulin resistance (HOMA-IR) and quantitative insulin sensitivity check index (QUICKI), lipid profile; serum cholesterol, triglycerides, very low density lipoprotein (VLDL-C), low density lipoprotein (LDL-C) and high density lipoprotein (HDL-C), LH, testosterone and SHBG.

Glucomannan shows highly significant decrease in weight, glucose, insulin level, HOMAB, HOMAIR, QUICKI, testosterone, LH, serum cholesterol, triglycerides, VLDL-C and LDL-C and highly significant increase in HDL-C and SHBG concentrations, no effect on BMI.

Glucomannan was effective in management of patients with PCOS through their ability to decrease the glucose, insulin levels, insulin resistance indexes, lipid profile, testosterone and $\mathrm{LH}$ and increase the HDL-C and SHBG.

PCOS, Glucomannan, obese, overweight, SHBG

Hussein ES, Abu-Raghif AR, Almuaid HA. Amorphophallus konjac and polycystic ovary syndrome. Iraqi JMS. 2020; 18(1): 61-69. doi: 10.22578/IJMS.18.1.9

List of abbreviations: GLUC = Glucomannan, HOMA = Homeostasis model assessment of insulin resistance, $\mathrm{LH}=$ luteinizing hormone, PCOS $=$ Polycystic ovary syndrome, SHBG = Sex hormone binding globulin

\section{Introduction}

U nder normal conditions, the hormone insulin rises briefly after eating. It stimulates the liver and muscles to take up sugar from the blood and convert it to energy. That then causes blood sugar to fall, and then insulin to fall. With normal insulin sensitivity, both sugar and insulin are normal on a fasting blood test. With insulin resistance, blood sugar may be normal, but insulin is high. Why? Because the pancreas has to make more and more insulin to try to get its message through. Too much insulin generates inflammation and causes weight gain. It can 
also lead to type 2 diabetes and heart disease. Too much insulin is also an underlying physiological driver of polycystic ovary syndrome (PCOS) ${ }^{(1)}$.

PCOS is a heterogeneous disorder that affects at least $7 \%$ of adult women, the National Institutes of Health Office of Disease Prevention, reported that PCOS affects approximately five million women of childbearing ageing the U.S. it is one of the leading causes one of the leading causes of female infertility (2).

Research submits that $6-11 \%$ of females; $18-44$ years of age are affected by PCOS, reproduction it the most common endocrine abnormality amongst women of reproductive age in the world. Women looking for help from health care professionals to resolve issues of obesity, acne, amenorrhea, excessive hair growth, and infertility often receive a diagnosis of PCOS. Women with PCOS have higher rates of endometrial cancer, cardiovascular disease, dyslipidemia, and type-2 diabetes mellitus (3).

It is a relationship between the presence of polycystic ovaries and signs of hirsutism, menstrual disturbances (e.g. amenorrhea, oligomenorrhea) and obesity (4).

Insulin resistance is a key feature of both obese and lean PCOS. It occurs in $70-95 \%$ of people with obese PCOS and $30-75 \%$ of people with lean PCOS, high insulin can impair ovulation and cause the ovaries to make excess testosterone ${ }^{(5)}$.

Glucomannan (GLUC), which is a soluble, fermentable, and highly viscous dietary fiber. It is derived from the root of konjac plant, which is native to Asia. GLUC consists of a polysaccharide chain of beta-di glucose and beta di mannose with attached acetyl groups in a molar ratio of 1:1.6 with beta 1-4 linkages. Then human salivary and pancreas amylase enzyme cannot split (beta 1, 4 linkages), GLUC passes relatively unchanged into the colon, where it is highly fermented by colonic bacteria (6).

GLUC has a high molecular weight and can absorb up to fifteen times its weight in water, it is considered one of the most viscous dietary fibers known. In the stomach, the GLUC turns into gelatin and induces a sense of satiety. Thus, GLUC inhibits the absorption of cholesterol and fats and reduce sugar absorption; it prevents the blood glucose peak by reducing the release of insulin from the pancreas and thus prevents hypoglycemia. It has been shown that GLUC long-term supplementation reduces fasting glucose and LDL cholesterol plasmatic levels in diabetic patients ${ }^{(7)}$.

The aim of this study is to explain the effectiveness of GLUC in the management of Iraqi women patients with PCOS.

\section{Methods \\ Patients}

This prospective study was conducted during the period from July 2018 to August 2019. The Ethics Committee of the Al-Nahrain Institutional Review Board Medical College approved this study. Women included in this study were among those who attended Clinic of Gynecology and Obstetrics in Al-Imamein AlKadhimein Medical Teaching City; Baghdad, Iraq, Patients were selected randomly according to the day of presentation to the clinic. All participants were given informed consent before they were included in this study.

The patients were; thirty women diagnosed with PCOS in their reproductive age (18-40 years). All the patients had at least 2 out of 3 of Rotterdom criteria.

Each patient was involved to detailed clinical history, physical examination and typical appearance of polycystic ovaries by ultrasound according to the criteria of Rotterdam consensus meeting 2003.

\section{Safety Assessment}

Safety assessment included medical history, physical examination, hormonal level, and serum chemistry at all visits and the monitoring of drug-related adverse events by recordation in patient diaries. 


\section{Laboratory investigations}

Weight, length, body mass index (BMI). [BMI = weight $(\mathrm{kg}) /$ height $(\mathrm{m})^{2}$ ].

Hormonal assays include sex hormone binding globulin (SHBG), testosterone, and luteinizing hormone (LH) by (TOSOH Corporation, Japan).

Fasting plasma glucose, serum insulin levels, insulin resistance indexes:

- HOMA-B = homeostasis model assessment of $\beta$-cell function; [HOMA$B=(20 x$ insulin in $\mathrm{mlU} / \mathrm{mL}) /$ (glucose in $\mathrm{mmol} / \mathrm{L}-3.5]$

- HOMA-IR = homeostasis model assessment of insulin resistance; [HOMA-IR = (glucose in $\mathrm{mmol} / \mathrm{L} \mathrm{x}$ insulin in $\mathrm{mIU} / \mathrm{mL}) / 22.5$ ]

- QUICKI = quantitative insulin sensitivity check index; [QUICKI $=1 /(\log$ [FIRI in $\mathrm{mU} / \mathrm{l}]+\log [$ [FP in $\mathrm{mg} / \mathrm{dl}]$ ).

Lipid profile: serum cholesterol, triglycerides, very low-density lipoprotein (VLDL-C), low density lipoprotein (LDL-C) and high-density lipoprotein (HDL-C) concentrations by (Selectra pro, Elitech, France).

\section{Study Design and Treatments}

The enrolled patients were asked to take 2300 mg of Gluc (NOW company, USA) orally for three months. Clinical examination, biochemical assay, and hormonal assay were performed at baseline and after three months of therapy. All patients provided their written informed consent and completed the entire trial.

\section{Statistical analysis}

The data were analyzed using Statistical Package for Social Sciences (SPSS) program version 25 by the National Opinion Research Center (NORC), at the University of Chicago. Results were reported as mean $\pm S D$. The total variations were analyzed by performing the statistical design t-test. Probability levels of less than 0.05 were considered significant.

\section{Results}

GLUC treatment was well-tolerated by all patients. None of the subjects suspended the therapy due to side effects, although some experienced transient flatulence during the first month of treatment. The mean weight and $\mathrm{BMI}$ decreased significantly during the treatment time, from $(88.90 \pm 8.41) \mathrm{kg}$ to $(81.21 \pm 7.68) \quad \mathrm{kg}, \quad(34.43 \pm 5.16) \quad \mathrm{kg} / \mathrm{m}^{2}$ to $(31.45 \pm 4.71) \mathrm{kg} / \mathrm{m}^{2}$ respectively (Table 1 ).

The results (Mean $\pm S D$ ) of glucose $(\mathrm{mg} / \mathrm{dL}$ ), insulin (ulU/ml), HOMAB, HOMAIR and QUICKI comparison of the GLUC group between before and after treatment show highly significant decrease $(p<0.001)$ in the values $(104.72 \pm 7.23$ vs. $84.48 \pm 5.96),(10.31 \pm 2.19$ vs. $6.64 \pm 0.70)$, $(119.48 \pm 32.52$ vs. $90.99 \pm 24.22),(2.67 \pm 0.61$ vs. $1.39 \pm 0.18), \quad(1.48 \pm 0.22$ vs. $1.34 \pm 0.05)$ respectively (Table 1 ).

In this study, results (mean $\pm S D$ ) before vs. after 3 months of treatment with GLUC of total cholesterol, triglycerides, LDL-C, VLDL-C, LH and testosterone show highly significant decrease $(p<0.001)$ in the values as $(173.71 \pm 10.54$ vs. $165.17 \pm 7.52),(131.48 \pm 6.32$ vs. $98.31 \pm 9.58)$, $(98.55 \pm 10.02$ vs. $80.97 \pm 6.76),(31.38 \pm 3.49$ vs. $27.00 \pm 2.39), \quad(23.09 \pm 3.52$ vs. $16.32 \pm 2.71)$, $(65.56 \pm 19.68$ vs. $31.59 \pm 8.87)$ respectively (Table 1) (Figures 1-4). Where the results (Mean \pm SD) before versus after 3 months of treatment with GLUC of HDL-C and SHBG showed highly significant increase $(p<0.001)$ in the values as $(43.78 \pm 3.67$ vs. $57.21 \pm 3.69)$, $(42.97 \pm 5.79$ vs. $57.04 \pm 6.83)$ respectively (Table 1) (Figures 5). 
Table 1. Comparison of weight, height, body mass index, glucose, insulin, insulin resistance indexes, lipid profile, LH, SHBG and Testosterone, in patients' group between before and after three months treatment of glucomannan

\begin{tabular}{cccc}
\hline Parameter & Before & Glucomannan & Pfter \\
\hline Wt $(\mathrm{kg})$ & $88.90 \pm 8.41$ & $81.21 \pm 7.68$ & 0.005 \\
BMI $\left(\mathrm{kg} / \mathrm{m}^{2}\right)$ & $34.43 \pm 5.16$ & $31.45 \pm 4.71$ & 0.012 \\
Glucose $(\mathrm{mg} / \mathrm{dl})$ & $104.72 \pm 7.23$ & $84.48 \pm 5.96$ & $<0.001$ \\
Insulin $(\mathrm{ulU} / \mathrm{ml})$ & $10.31 \pm 2.19$ & $6.64 \pm 0.70$ & $<0.001$ \\
HOMAB & $90.99 \pm 24.22$ & $119.48 \pm 32.52$ & 0.010 \\
HOMAIR & $2.67 \pm 0.61$ & $1.39 \pm 0.18$ & $<0.001$ \\
QUICKI & $1.48 \pm 0.22$ & $1.34 \pm 0.05$ & $<0.001$ \\
TG $(\mathrm{mg} / \mathrm{dL})$ & $131.48 \pm 6.32$ & $98.31 \pm 9.58$ & $<0.001$ \\
Cholesterol $(\mathrm{mg} / \mathrm{dL})$ & $173.71 \pm 10.54$ & $165.17 \pm 7.52$ & 0.001 \\
VLDL-C $(\mathrm{mg} / \mathrm{dL})$ & $31.38 \pm 3.49$ & $27.00 \pm 2.39$ & $<0.001$ \\
LDL-C $(\mathrm{mg} / \mathrm{dL})$ & $98.55 \pm 10.02$ & $80.97 \pm 6.76$ & $<0.001$ \\
HDL-C $(\mathrm{mg} / \mathrm{dL})$ & $43.78 \pm 3.67$ & $57.21 \pm 3.69$ & $<0.001$ \\
LH $(\mathrm{mlU} / \mathrm{ml})$ & $23.09 \pm 3.52$ & $16.32 \pm 2.71$ & $<0.001$ \\
Testosterone $(\mathrm{mlU} / \mathrm{ml})$ & $65.56 \pm 19.68$ & $31.59 \pm 8.87$ & $<0.001$ \\
SHBG $(\mathrm{mlU} / \mathrm{ml})$ & $42.97 \pm 5.79$ & $57.04 \pm 6.83$ & $<0.001$ \\
\hline
\end{tabular}

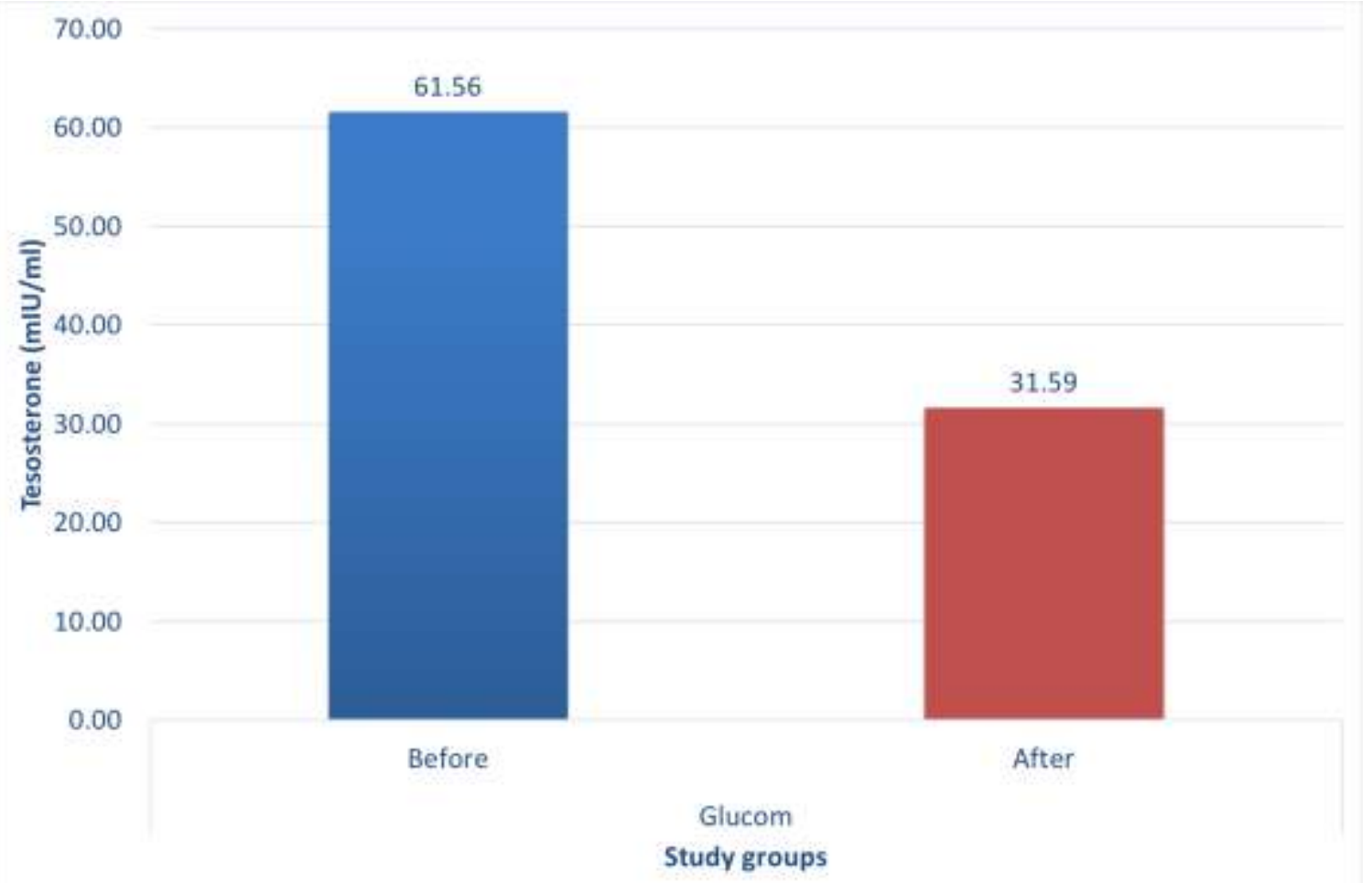

Figure 1. Comparison of mean Testosterone $(\mathrm{mlU} / \mathrm{ml})$ between study group before and after treatment 
Iraqi JMS 2020; Vol. 18(1)

120.00

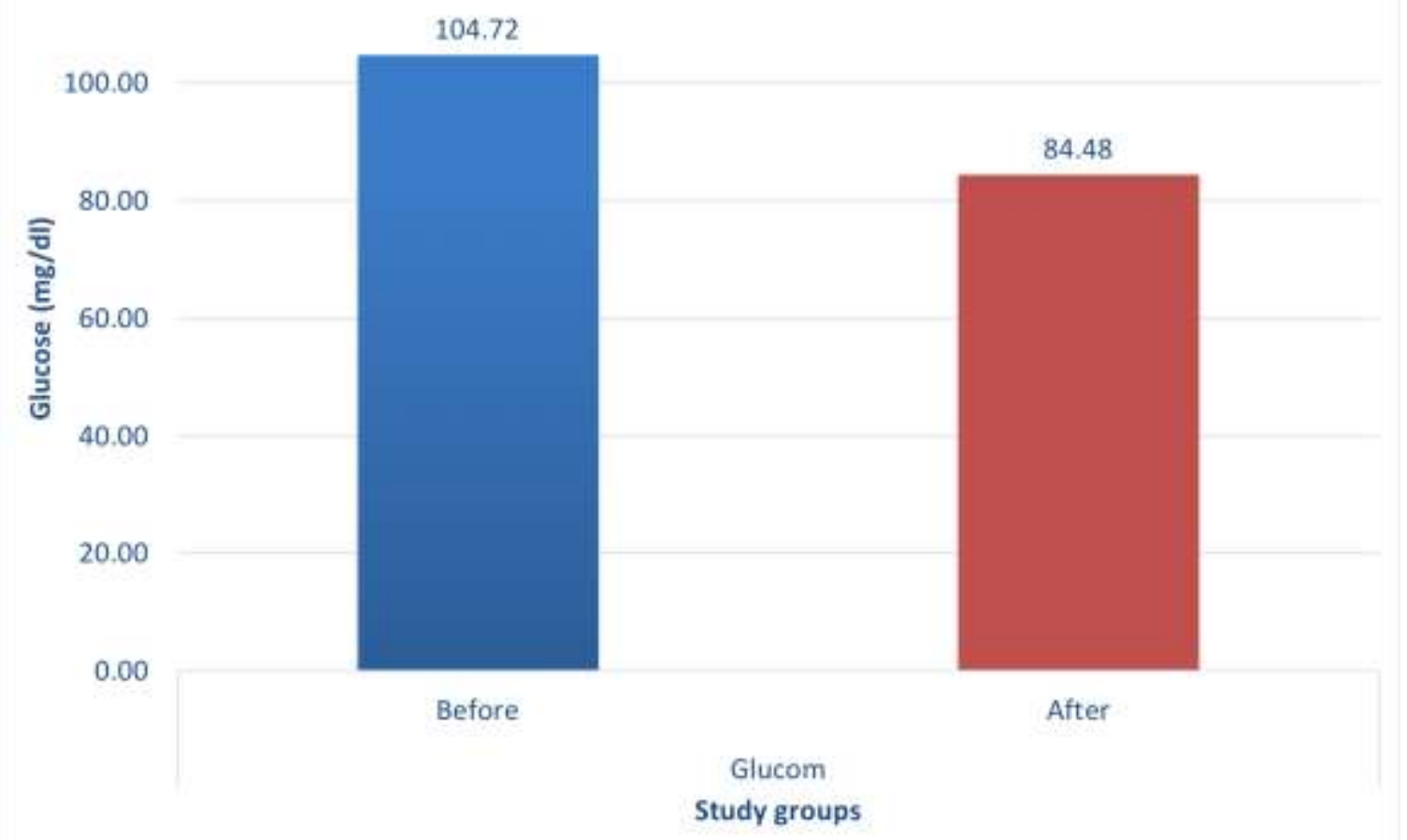

Figure 2. Comparison of mean glucose $(\mathrm{mg} / \mathrm{dl})$ between study group before and after treatment

12.00

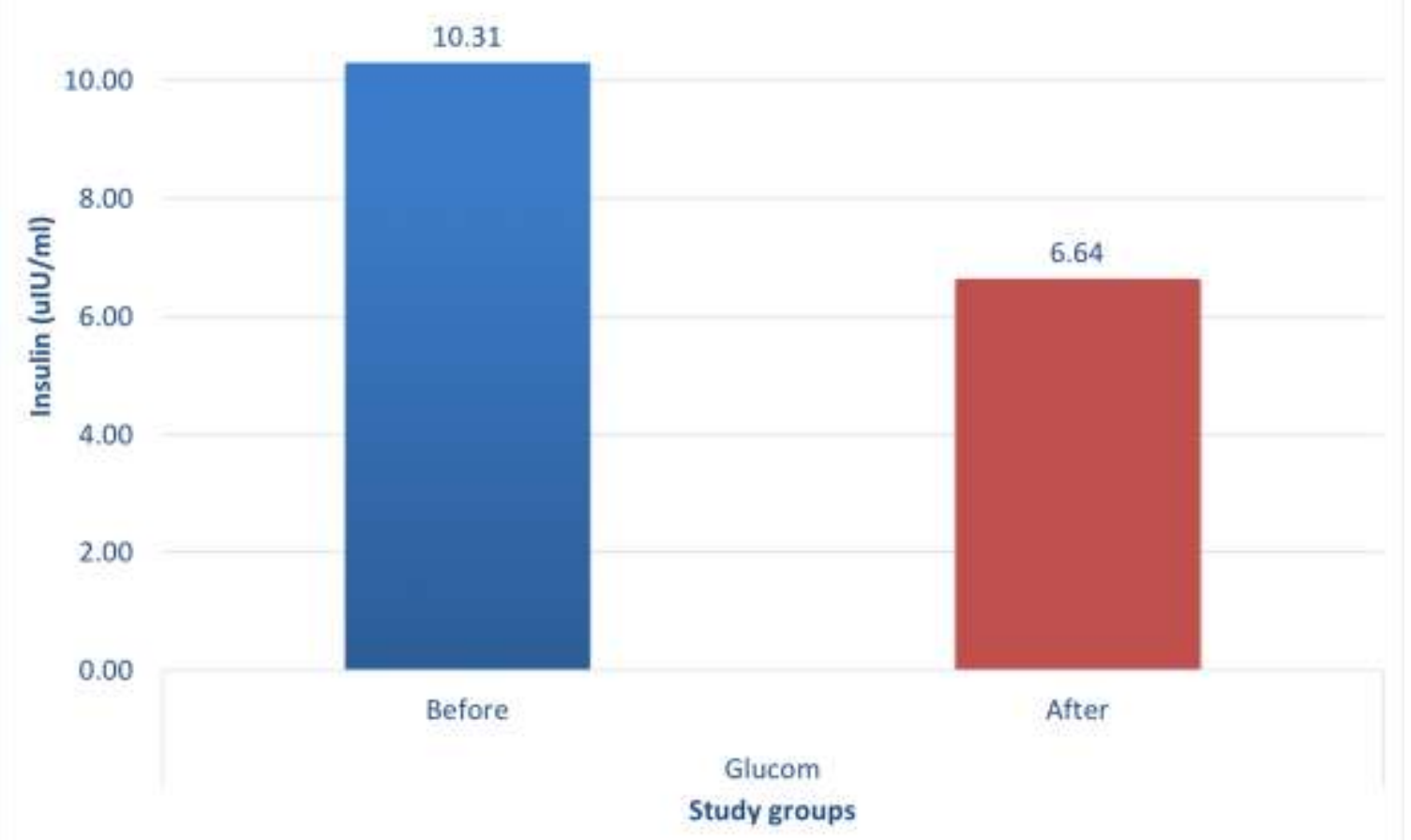

Figure 3. Comparison of mean insulin $(\mathrm{mlU} / \mathrm{ml})$ between study group before and after treatment 
Hussein et al, Amorphophallus konjac in POC

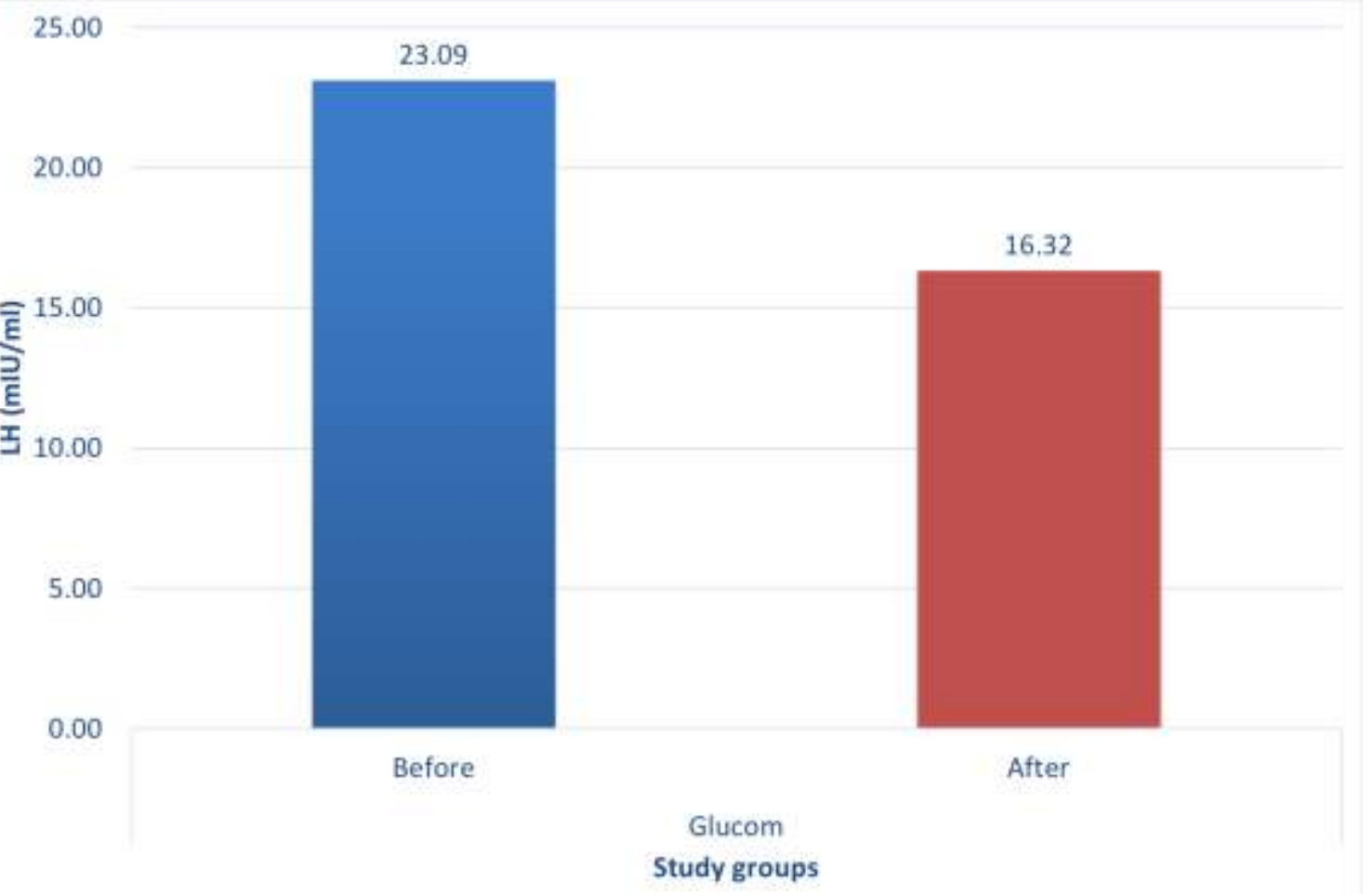

Figure 4. Comparison of mean luteinizing hormone $(\mathrm{mlU} / \mathrm{ml})$ between study group before and after treatment

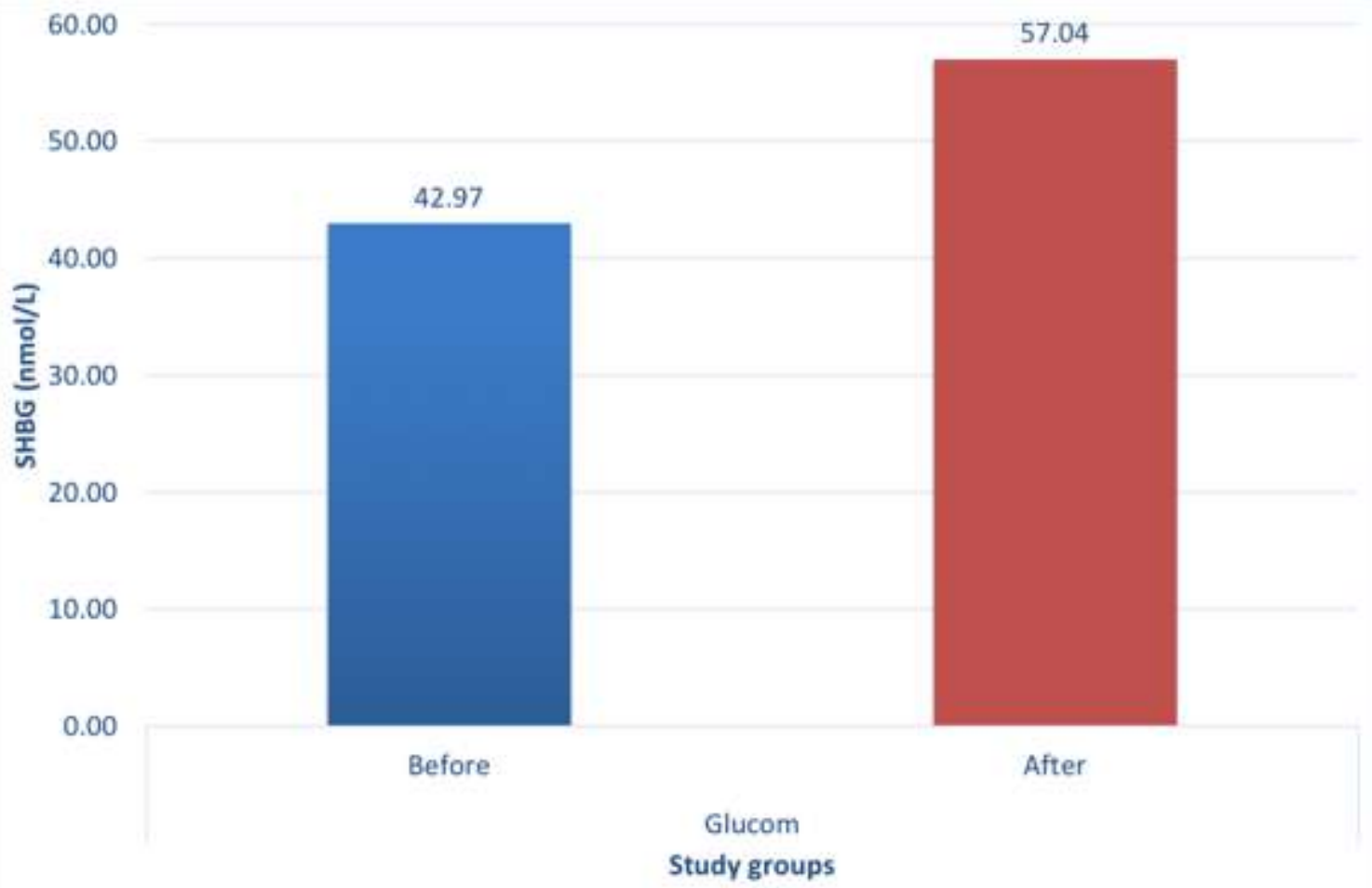

Figure 5. Comparison of mean sex hormone binding globulin ( $\mathrm{nmol} / \mathrm{L}$ ) between study group before and after treatment 


\section{Discussion}

PCOS is multifaceted disorder have neuroendocrine and ovarian dysfunction, high incidence of metabolic disorder, such as obesity and glucose intolerance ${ }^{(4,8)}$.

The results (Mean $\pm S D$ ) of glucose $(\mathrm{mg} / \mathrm{dL})$, insulin (uIU/ml), HOMAB, HOMAIR and QUICKI comparison of the GLUC group between before and after treatment show highly significant decrease $(p<0.001)$. The high insulin level stimulates the thecal and stromal cells of ovarian to secrete androgen (9). The insulin resistance with compensatory hyperinsulinemia, leading to hyper androgenism. The action of insulin on the production of androgens in the ovary is thought to be through insulin like growth factor-1 (IGF-1) receptors on theca and stromal cells ${ }^{(10,11)}$.

In recent years in Iraq, PCOS has become a very common disease due to the complicated lifestyle of social and environmental conditions and the lack of societal culture towards proper nutrition, so stress, bad eating habit, sweets and gaseous drinks has a role in increasing cases of PCOS between the women.

The mean weight and BMI decreased significantly during the treatment time due to GLUC is a water-soluble fiber, it's encouraged weight loss in several ways; it is very low in calories (12). It takes space in stomach and promotes a feeling of fullness (satiety) then reducing food intake and delays stomach emptying time, due to increased satiety ${ }^{(13)}$.

One of the studies showed a correlation between altered gut bacteria and body weight, it mentioned that GLUC enhances the good bacteria in your intestine, which due to short chain fatty acids like butyrate that protect against fat gain in some animal studies ${ }^{(14)}$.

GLUC differs from other soluble fibers, as it's especially viscous, making it effective for weight loss. Weight reduction was significantly greater among those who supplemented with GLUC (15).

Many other studies agree with these results. GLUC caused modest weight loss in overweight and obese individuals when regularly ingested before a meal $(16,17)$.
In the gastrointestinal tract GLUC conforms to gelatin and induces a satiety. It inhibits the absorption of cholesterol, fats and decrease sugar absorption; it prevents the blood glucose increasing by reducing the release of insulin from the pancreas, this wonderful in part to better control of glucose and reduce insulin resistance ${ }^{(6,18,19)}$.

Many studies have steadily shown that GLUC taken with a meal significantly reduces the glucose and insulin response by as much as one-half., adding GLUC to your diet could potentially lower your risk of developing heart disease and type 2 diabetes ${ }^{(18)}$.

GLUC reduces plasma glucose level and make alteration of plasma insulin when taken in obese and healthy subjects. Insulin resistance indexes were decreased in female subjects taking GLUC but increase in the placebo-taking females (20).

GLUC appears to beneficially affect total cholesterol, LDL-C, triglycerides, body weight, and FBG, but not blood pressure ${ }^{(21)}$.

Insulin sensitivity or $\beta$-cell function, according to HOMA-IR, QUICKI and HOMA-B indexes show change after treatment; however, significantly $(p<0.001)$ in GLUC group. This agrees with, an increased response to insulin and reduction in glycemia in diabetic patients consuming GLUC (22).

In this study, the patients in group that receiving GLUC show decreased in total cholesterol, LDL-C, triglycerides and increased in HDL-C. These results agree with study reported that cardiovascular benefits of GLUC are due to its effect on lipids. Studies have shown that GLUC is not only statistically significant, but probable is also clinically significant ${ }^{(23)}$.

These effects on total cholesterol, LDL-C, and HDL-C are comparable to those observed several meta-analysis studies that suggests effect of soluble fibers demonstrate reductions in triglycerides with soluble fibers. The cause of GLUC ability to especially lower triglycerides compared with other soluble fibers is not known, probable due to higher viscosity and its ability to alter the metabolic pathways of hepatic cholesterol and lipoprotein metabolism (24), increased fecal neutral sterol and bile acid 
contents thus improving blood lipid levels (25). Compared to other gel-forming fibers, GLUC has three-to five folds stronger lipid-lowering effect (26). Two previous studies showed Glucomannan and others soluble fiber believed to decrease the risk of cardiovascular disease risk by modifying plasma lipids (27).

Patients getting GLUC had statistically significantly lower total cholesterol, LDL-C cholesterol, triglycerides, body weight, and fasting glucose level, it is having greatest cardiovascular benefits due to its effect on lipids profile ${ }^{(23)}$.

This research is a novel due to first time studying the GLUC effects on women with PCOS, we see a significant statistical difference in the hormones levels testosterone, $\mathrm{LH}$ and SHBG in the GLUC group before and after treatment ( $p \leq 0.001)$; the effects of the GLUC on the hormones were probably due to GLUC have a hypoglycemic effect to lower blood glucose level and decrease the insulin resistance lead to decrease in ovarian androgen level, free testosterone, increase SHBG, decrease hypothalamic GnRH pulses, and this lead to low in the LH level ${ }^{(28)}$.

Administration of an insulin sensitizing agent has beneficial role in lowering serum testosterone level by exerting its action over serum insulin and increasing insulin sensitivity of tissues in PCOS (18).

The benefit of GLUC in PCOS treatment as a fiber supplement should be used to get a significant weight reduction. In addition, reduces fasting glucose increment, improve insulin sensitivity and decrease an elevation of serum lipids (29).

GLUC was effective in management of patients with PCOS throw their ability to decrease the glucose, insulin levels, insulin resistance, lipid profile, testosterone and $\mathrm{LH}$ and increase the HDL and SHBG.

\section{Acknowledgement}

The authors like to thank Dr. khalid Mohamed Wahed, Dr. Zahid Mohamed \& Mr. Ali Abdul Ameer for supporting this project.

\section{Author contribution}

Hussein: Acquisition of data with participation. All authors participated in the design of the study, analysis, interpretation of data and writing of the manuscript.

\section{Conflict of interest}

The authors declare no conflict of interest.

\section{Funding}

Self-funding.

\section{References}

1. Lin LH, Baracat MC, Maciel GA, et al. Androgen receptor gene polymorphism and polycystic ovary syndrome. Int J Gynaecol Obstet. 2013; 120(2): 1158. doi: 10.1016/j.ijgo.2012.08.016.

2. Aubuchon $M$, Legro RS. Polycystic ovary syndrome: current infertility management. Clin Obstet Gynecol. 2011; 54(4): 675-84. doi: 10.1097/GRF.0b013e3182353c98.

3. McFarland C. Treating polycystic ovary syndrome and infertility. MCN Am J Matern Child Nurs. 2012; 37(2): 116-21. doi: 10.1097/NMC.0b013e31824239ce.

4. Moran L, Misso ML, Wild RA, et al. Impaired glucose tolerance, type 2 diabetes and metabolic syndrome in polycystic ovary syndrome: a systematic review and meta-analysis. Hum Reprod Update. 2010; 16(4): 347-63. doi: 10.1093/humupd/dmq001.

5. Pericleous $\mathrm{P}$, Stephanides $\mathrm{S}$. Can resistance training improve the symptoms of polycystic ovary syndrome? BMJ Open Sport Exerc Med. 2018; 4(1): e000372. doi: 10.1136/bmjsem-2018-000372.

6. Shimahara $H$, Suzuki $H$, Sugiyama $N$ et al. Isolation and characterization of oligosaccharides from an enzymic hydrolysate of konjac glucomannan. Agricult Biol Chem. 1975; 39(2): 293-9. doi: 10.1080/00021369.1975.10861604.

7. Chearskul S, Sangurai S, Nitiyanant W, et al. Glycemic and lipid responses to glucomannan in Thais with type 2 diabetes mellitus. J Med Assoc Thai. 2007 Oct; 90(10): 2150-7.

8. Blank SK, McCartney CR, Marshall JC. The origins and sequelae of abnormal neuroendocrine function in polycystic ovary syndrome. Hum Reprod Update. 2006 Jul-Aug; 12(4): 351-61. doi: 10.1093/humupd/dml017.

9. Stepto NK, Cassar S, Joham AE, et al. Women with polycystic ovary syndrome have intrinsic insulin resistance on euglycaemic-hyperinsulaemic clamp. Hum Reprod. 2013; 28(3): 777-84. doi: 10.1093/humrep/des463.

10. Randeva HS, Tan BK, Weickert MO, et al. Cardiometabolic aspects of the polycystic ovary syndrome. Endocr Rev. 2012; 33(5): 812-41. doi: 10.1210/er.2012-1003. 
11. Firmansyah A, Chalid MT, Farid RB, et al. The correlation between insulin-like growth factor binding protein 1 (IGFBP-1) and homeostasis model assessment of insulin resistance (HOMA-IR) in polycystic ovarian syndrome with insulin resistance. Int J Reprod Biomed. 2018; 16(11): 679-682.

12. Brown L, Rosner B, Willett WW, et al. Cholesterollowering effects of dietary fiber: a meta-analysis. Am J Clin Nutr. 1999; 69(1): 30-42. doi: 10.1093/ajcn/69.1.30. PMID: 9925120.

13. Baer DJ, Rumpler WV, Miles CW, et al. Dietary fiber decreases the metabolizable energy content and nutrient digestibility of mixed diets fed to humans. J Nutr. 1997; 127: 579-586.

14. Gao Z, Yin J, Zhang J, et al. Butyrate improves insulin sensitivity and increases energy expenditure in mice. Diabetes. 2009; 58(7): 1509-17. doi: 10.2337/db081637.

15. Birketvedt GS, Shimshi M, Erling $T$, et al. Experiences with three different fiber supplements in weight reduction. Med Sci Monit. 2005; 11(1): PI5-8.

16. Keithley J, Swanson B. Glucomannan and obesity: a critical review. Altern Ther Health Med. 2005; 11(6): 30-4.

17. Horvath A, Dziechciarz P, Szajewska H. Glucomannan for abdominal pain-related functional gastrointestinal disorders in children: a randomized trial. World J Gastroenterol. 2013; 19(20): 3062-8. doi: 10.3748/wjg.v19.i20.3062.

18. Keithley JK, Swanson B, Mikolaitis SL, et al. Safety and efficacy of glucomannan for weight loss in overweight and moderately obese adults. J Obes. 2013; 2013: 610908. doi: 10.1155/2013/610908.

19.Zalewski BM, Szajewska H. Effect of glucomannan supplementation on body weight in overweight and obese children: protocol of a randomised controlled trial. BMJ Open. 2015; 5(4): e007244. doi: 10.1136/bmjopen-2014-007244.

20. Al-Ghazzewi FH, Tester RF. Efficacy of cellulase and mannanase hydrolysates of konjac glucomannan to promote the growth of lactic acid bacteria. J Sci Food Agric. 2012; 92(11): 2394-6. doi: 10.1002/jsfa.5678.

21. Sood N, Baker WL, Coleman Cl. Effect of glucomannan on plasma lipid and glucose concentrations, body weight, and blood pressure: systematic review and meta-analysis. Am J Clin Nutr. 2008; 88(4): 1167-75. doi: 10.1093/ajcn/88.4.1167.
22. Wallace TM, Levy JC, Matthews DR. Use and abuse of HOMA modeling. Diabetes Care. 2004; 27(6): 148795. doi: 10.2337/diacare.27.6.1487.

23. Grundy SM, Cleeman JI, Merz CN, et al. Implications of recent clinical trials for the National Cholesterol Education Program Adult Treatment Panel III guidelines. Circulation. 2004; 110(2): 227-39. doi: 10.1161/01.

24. Cheang $\mathrm{KU}$, Chen $\mathrm{CM}$, Chen CYO, et al. Effects of glucomannan noodle on diabetes risk factors in patients with metabolic syndrome. J Food Nutr Res. 2017; 5(8): 622-8.

25. Chen HL, Sheu WH, Tai TS, et al. Konjac supplement alleviated hypercholesterolemia and hyperglycemia in type 2 diabetic subjects--a randomized doubleblind trial. J Am Coll Nutr. 2003; 22(1): 36-42. doi: 10.1080/07315724.2003.10719273.

26. Vuksan V, Sievenpiper JL, Owen R, et al. Beneficial effects of viscous dietary fiber from Konjac-mannan in subjects with the insulin resistance syndrome: results of a controlled metabolic trial. Diabetes Care. 2000; 23(1): 9-14. doi: 10.2337/diacare.23.1.9.

27. Anderson JW, Allgood LD, Lawrence $A$, et al. Cholesterol-lowering effects of psyllium intake adjunctive to diet therapy in men and women with hypercholesterolemia: meta-analysis of 8 controlled trials. Am J Clin Nutr. 2000; 71(2): 472-9. doi: 10.1093/ajcn/71.2.472.

28. Shimizu $H$, Yamauchi $M$, Kuramoto $T$, et al. Effects of dietary konjac mannan on serum and liver cholesterol levels and biliary bile acid composition in hamsters. J Pharmacobiodyn. 1991; 14(7): 371-5. doi: 10.1248/bpb1978.14.371.

29. Wu WT, Chen HL. Konjac glucomannan and inulin systematically modulate antioxidant defense in rats fed a high-fat fiber-free diet. J Agric Food Chem. 2011; 59(17): 9194-200. doi: 10.1021/jf202060p.

\section{Correspondence to Ehab S. Hussein \\ E-mail: dr_albawy@yahoo.com \\ Received Jun. 21 2020 \\ Accepted Sep. $1^{\text {st }} 2020$}

